\title{
As edições especiais da coleção Biblioteca de Literatura Brasileira, publicadas pela Livraria Martins Editora
}

The special editions of the Brazilian Literature Library Collection, published by Livraria Martins Editora in the 1940s

NASTARI ZENI, Sílvia de Moraes; Mestranda; FAU-USP

silvianastari@gmail.com

BRAGA, Marcos da Costa; Doutor em História Social; FAU USP

bragamcb@usp.br

\section{Resumo}

A Livraria Martins, pequena livraria especializada na importação de livros, na sua maioria exemplares raros, vindos da França, Inglaterra e Estados Unidos, começou suas atividades em 1937, em São Paulo. Após dois anos, José de Barros Martins inaugurou a Livraria Martins Editora e começou a editar seus próprios livros. Dentre as coleções da editora, a Biblioteca de Literatura Brasileira (1940-1950) se destacou por suas edições especiais, as quais se diferenciavam da tiragem em maior escala e eram destinadas a um público leitor específico: colecionadores, bibliófilos e leitores da elite social. A partir da análise gráfica das edições especiais da coleção e do contexto histórico-social em que foram publicadas na década de 1940, este trabalho tem como objetivo entender as motivações do editor em criar uma coleção para articular edições de luxo e edições comerciais do mesmo título como estratégia editorial e de comercialização dos livros.

Palavras Chave: história do design; projeto gráfico, memória gráfica

\section{Abstract}

Livraria Martins, a bookstore specialized in importing books, mostly rare copies, from France, England and the United States, started its activities in 1937 in São Paulo. After two years, José de Barros Martins opened the Livraria Martins Editora (publishing house and bookstore) and began to edit his own books. Among its collections, the Biblioteca de Literatura Brasileira (Brazilian Literature Library), 1940-1950, stood out for its special editions, as they were different from the large scale printing and were targeted to a specific audience: collectors, bibliophiles and readers of the social elite. From the graphical analysis of the 1940 series, this work had the objective of understanding the editor's motivation to put together deluxe and commercial editions with of luxury and commercial editions of the same title as editorial strategy and marketing of the books.

Keywords: design history; graphic design, brazilian graphic memory 


\section{Introdução}

Entre os anos de 1941 e 1955 a Livraria Martins Editora publicou a coleção Biblioteca de Literatura Brasileira. Neste período, foram lançados 15 títulos, os quais, posteriormente, foram reeditados e vendidos em conjunto, num formato de edições colecionáveis. Em aspectos gerais, a coleção $\mathrm{BLB}^{1}$ se define por: publicar os cânones da literatura brasileira, ou seja, os autores considerados consagrados pelo público e crítica, com introduções de estudiosos renomados; ter seus exemplares ilustrados por grandes nomes da arte brasileira ou ilustradores (artistas que estavam despontando como ilustradores de livros); e, por fim, receber um tratamento gráfico especial, com boa impressão tipográfica e papel de qualidade. O design gráfico da coleção BLB e o acabamento dos livros eram fatores de grande importância para o editor. O gosto pelo livro bem feito se deve, dentre outras razões, ao fato de José de Barros Martins ter tido muito contato com as edições de luxo que importava da França e da Inglaterra.

Aspecto significativo da coleção - objeto de estudo deste trabalho - são as tiragens especiais ${ }^{2}$, também denominadas pela editora como "edição especial" e "edição de luxo", as quais se diferenciavam das "edições comuns". Neste trabalho optou-se por utilizar tanto no título quanto nas referências às tiragens especiais, o termo "edição especial" " , uma vez que ele é recorrente nas "justificativas de tiragens", encontradas nos livros da Editora Martins, como também pelo fato de, atualmente, as editoras utilizarem o termo para se referirem aos livros de características semelhantes.

O escopo da pesquisa foi selecionado em razão do recorte temporal - as edições da coleção BLB publicadas entre os anos de 1941-1947 -, uma vez que todos os livros produzidos na década de 1940 fazem distinções de edições (especial x comum), tais como: qualidade do papel, numeração do exemplar à mão, assinatura do editor, inserção de uma gravura original etc. Para este trabalho foram consultados nove livros de um total de quinze livros da coleção BLB e, a partir da observação e manuseio direto das edições originais, foi possível reunir um conjunto para a identificação das variações gráficas e editorias que ocorreram.

\section{Livraria Martins, de importadora a editora de livros}

José de Barros Martins era funcionário do Banco do Brasil e frequentava o curso de filosofia na Faculdade de Filosofia e Letras da Universidade de São Paulo. No entanto,

\footnotetext{
${ }^{1}$ A abreviação BLB será utilizada para se referir à coleção Biblioteca de Literatura Brasileira.

2 O termo "tiragens especiais" será adotado neste trabalho de acordo com a definição do verbete do Dicionário do livro: parte de uma tiragem normal, executada em bom papel, com numeração própria, muitas vezes com a assinatura do autor e na qual consta o número total de exemplares desta tiragem. (FARIA, PERIÇÃO, 2008, p.704).

3 Visto que "nada é mais confuso do que o uso da palavra edição, que pode estender-se a todos os exemplares de uma obra produzidos por um mesmo editor (a edição Michel Levy de Madame Bovary), mesmo que o texto tenha sido modificado várias vezes na hora das reimpressões, ou limitar-se, como os editores gostam às vezes de fazer por razões publicitárias, a cada série de mil, ou quinhentos exemplares da mesma tiragem. Tecnicamente, os únicos termos precisos são os de composição e tiragem, ou de impressão. Com uma mesma composição tipográfica, pode-se fazer, salvo desgaste, um número indefinido de tiragens, e portanto, de séries de exemplares em princípio idênticos. Mas cada tiragem pode ser o momento de correções de detalhe, e a época clássica não se privava até mesmo de correções no curso da tiragem, as quais introduziam diferenças de texto dentro de uma mesma série. (GENETTE, 2009 , p.36 apud LAUFER, Introdução à textologia, São Paulo, Perspectiva, 1980).
} 
antes de terminar seus estudos, optou por trocar pelo curso de direito na mesma universidade. Assíduo frequentador de bibliotecas, sebos e livrarias, em 5 de abril de 1937, o futuro editor, se demite do emprego no banco e abre na sobreloja de um prédio na Rua da Quitanda, $n^{0} 82$, no centro de São Paulo, uma pequena livraria especializada em livros importados da França, Inglaterra e Estados Unidos. Segundo Mário da Silva Brito, Martins, grande frequentador dos sebos e livrarias da cidade, "percebeu que muita coisa faltava em suas prateleiras, especialmente da produção internacional. Passou a importar livros não só para o seu uso pessoal como também para o de amigos. Dessa prática nasceu a ideia de montar uma livraria". 4

Outros fatores, como a criação do Departamento de Cultura, dirigido por Mário de Andrade e as dificuldades de importação durante a Segunda Guerra Mundial também foram decisivos nesse processo. De acordo com Hallewell, a desvalorização da moeda, entre os anos de 1930-1935, afetou o mercado de importação de livros, no entanto, havia grande demanda por grande parte do público comprador por edições francesas. $\mathrm{O}$ autor também nos fornece um panorama do tipo de livro comercializado pela importadora e os frequentadores da Livraria Martins:

\begin{abstract}
"A especialidade de Martins eram as edições de luxo, apesar de ter arrematado em Paris, estoques de liquidação de livros comuns em leilões, para oferecer negócios vantajosos a seus fregueses menos ricos. Seu estoque total era bastante reduzido, mas selecionado criteriosamente, de modo que sua loja logo se tornou um local regular de encontro dos bibliófilos da cidade. Importava também da Inglaterra e dos Estados Unidos, mantendo um estoque em língua inglesa tão bom que seu estabelecimento tornou-se também a livraria mais popular entre os americanos e britânicos residentes em São Paulo". (Hallewell, 2005, p.501)
\end{abstract}

As pessoas que circulavam pela Livraria Martins faziam parte da elite paulistana e logo a livraria se tornou um ponto de encontro de intelectuais e acadêmicos. Para suprir a ausência de uma bibliografia especializada usada nos cursos recém abertos na capital paulista como os da Escola Livre de Sociologia e Polícia (ELSP), fundada em 1933, e da Universidade de São Paulo, inaugurada em 1934, e, também, por conta da influência e bagagem cultural de professores estrangeiros que estavam em São Paulo, como por exemplo Claude Lévi-Strauss, Fernand Braudel e Roger Bastide, José de Barros Martins começou a fazer a transição da empresa importadora de livros para a editora. Por um certo período, Martins manteve em funcionamento tanto a livraria quanto a editora. ${ }^{5}$

\title{
3 Os livros importados e as primeiras publicações da editora
}

Os livros que a Livraria Martins importava - em sua maioria edições de luxo -, vinham da França, Inglaterra e Estados Unidos e atraíam consumidores diferenciados. Mário da Silva Brito, em relato sobre os trinta anos da editora, relembra que muitas das edições de luxo que a livraria vendia eram, até então, importadas diretamente pelos próprios compradores e, quando a Martins começa a comercializá-las, as edições "chegam a São Paulo em quantidade razoável, permitindo-se, por seu preço acessível, a

\footnotetext{
${ }^{4}$ BRITO, 1967, p.16.

5 Outra informação que evidencia a livraria-editora é a indicação tanto da loja, localizada na Rua 15 de Novembro, 135, quanto da editora, estabelecida na Rua São Francisco, 77 e 81, ambas na região central de São Paulo.
} 
sua difusão entre um público maior. É o caso das obras de Balzac, Verlaine, Flaubert, Stendhal, Gerard de Nerval e outras, publicadas pelas editoras francesas Librarie de France e Éditions du Trianon". 6 La philosophie, obra do escritor francês Georges Courteline, lançada em 1930 pela Éditions du Trianon, é um exemplo das edições publicadas pela editora francesa. ${ }^{7}$ Nas imagens reproduzidas abaixo temos uma referência do design gráfico da capa e de páginas do miolo, em que se vê uma das ilustrações em aquarela feita por Joseph Hémard (Figura 1).

Figura 1 - Capa e páginas de La Philosophie, livro publicado em 1930 pela Éditions du Trianon
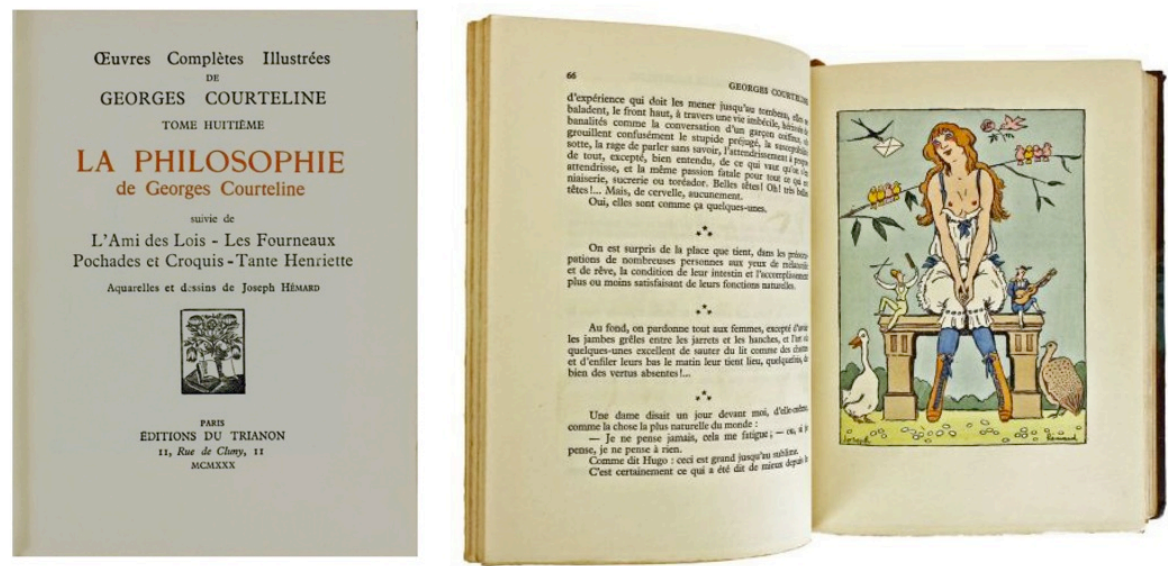

Fonte: http://www.drartesleiloes.com.br/peca.asp?ID=1870724\&ctd=18\&tot=\&tipo=95

Ao mesmo tempo que as edições estrangeiras eram importadas e comercializadas, o primeiro título lançado pela Livraria Martins Editora foi Direito Social Brasileiro, de Antônio Ferreira Cesarino Júnior. Em seguida, é publicado Viagem Pitoresca Através do Brasil, de Johann Moritz Rugendas. Ambos os títulos retratam o momento político-social do período como também antecipam caraterísticas que irão consolidar mais adiante no catálogo da editora. Ao lançar a obra de Cesarino Júnior, que foi professor de Direito da Faculdade de São Paulo e percursor do direito do trabalho no Brasil, o editor José de Barros Martins mostra como estava atento às demandas para edição de estudos acadêmicos como também para temas nacionais relevantes, como a consolidação das leis trabalhistas realizadas por Getúlio Vargas. Por outro lado, ao publicar a obra do viajante Johann Moritz Rugendas em 1865, traduzida por Sérgio Milliet, com a reprodução das cento e dez litogravuras originais, o editor aponta para um outro aspecto da realidade na época: a necessidade de se entender o Brasil resgatando importantes obras históricas. A obra Viagem Pitoresca Através do Brasil, de Rugendas, foi o primeiro título da coleção Biblioteca Histórica Brasileira, dirigida pelo bibliófilo Rubens Borba de Moraes. A coleção também inaugura na Martins o seu projeto mais ambicioso: a edição de livros nacionais de qualidade em escala comercial.

\footnotetext{
${ }^{6}$ Idem 4, p.16.

${ }^{7}$ Não há como confirmar se José de Barros Martins importou especificamente este título, visto que até o momento não foi localizado um catálogo das obras importadas pela Livraria Martins Importadora, porém levando em consideração a data da edição (1930) publicada pela Éditions du Trianon, o exemplo é válido por nos apresentar o aspecto visual dos livros produzidos pela editora francesa no período mencionado por Mario da Silva Brito.
} 
A necessidade de ampliar e diversificar a produção da Martins, impulsionou o editor a lançar no mesmo período as coleções Biblioteca do Pensamento Vivo, Excelsior, Excelsior Gigante, Mosaico, Biblioteca de Ciências Sociais, Biblioteca de Literatura Brasileira e Biblioteca Histórica Paulista.

\title{
4. O que define uma edição especial?
}

De acordo com o verbete "edição especial", encontrado no Dicionário do livro, de autoria de Maria Isabel Faria e Maria da Graça Pericão, temos a seguinte definição:

\begin{abstract}
diz-se da edição de uma obra clássica ou das obras de um autor clássico reimpressa com outro formato, compreendendo por vezes uma introdução, notas, apêndices, ilustrações e apresentando com frequência um novo título - diz-se de uma edição que se distingue da edição vulgar, quer pela qualidade do papel e da encadernação, quer pela adição de ilustrações; edição extra; edição extraordinária - número extra ou aumentado de uma publicação periódica ou outra dedicado a determinado assunto, cidade, país, região ou editado quando de um aniversário, Natal, etc.; número especial. (FARIA, PERIÇÃO, 2008, p.267)
\end{abstract}

Neste sentindo, a coleção BLB, lançada na década de 1940, contempla a maioria dos aspectos de "edição especial", definidos acima, ao publicar os autores clássicos da literatura brasileira, com textos críticos e ilustrações de artistas modernistas, em tiragens que faziam a seguinte distinção: de uma tiragem total de 2.120 exemplares, os 120 primeiros números eram impressos com papel especial, poderiam conter uma gravura original, uma "suíte" em sépia com a reprodução de todas as ilustrações ao final do livro e, também, a assinatura do autor (caso estivesse vivo) ou do editor José de Barros Martins. A tiragem limitada era comercializada e vendida a $40 \$ 000$. Preço bem mais alto que o aplicado para o restante da tiragem, denominada "edição comum", que era vendida por valores que variavam entre $15 \$ 000$ a $20 \$ 000$, em moeda da época. ${ }^{8}$

Segundo, Gérard Genette, as tiragens de "luxo" de uma edição se constituem a partir da escolha do papel, da numeração dos exemplares e outras "manobras de singularização" por parte do editor que aumentam o valor do objeto livro. Para o autor, enquanto a composição tipográfica da obra é a materialização do texto, o papel é tãosomente um suporte dessa materialização. A variação do papel numa mesma tiragem representa, objetivamente, diferenças de ordem estética (qualidade do papel e da impressão), econômica (valor de mercado de um exemplar) e, às vezes material (maior ou menor longevidade). Mas, servem também, e talvez acima de tudo, para motivar uma diferença simbólica capital, que diz respeito ao "caráter" limitado dessas tiragens. (GENETTE, 2009, p.36-37). A partir desse ponto de vista, o livro em edição especial e limitada adquire status de raro, um status atribuído de antemão pelo editor, que já o produz com o intuito de torná-lo objeto desejado por colecionadores, bibliófilos e leitores. Estes, ao adquirirem o livro e se inserirem no circuito literário, mesmo que apenas como consumidores, buscam se diferenciar em "disputas de distinção, ampliando os usos e significados possíveis do objeto-livro”. (SORÁ, 2010, p. 370).

Em 1943, Francisco de Assis Barbosa, historiador e jornalista que acompanhou de perto a produção da Livraria Martins Editora, nos fornece um testemunho da recepção

\footnotetext{
${ }^{8}$ HALLEWELL, 2005, p.503.
}

$13^{\circ}$ Congresso Brasileiro de Pesquisa e Desenvolvimento em Design, Univille, Joinville (SC) 
das edições especiais produzidas por José de Barros Martins no período:

O livro de luxo é, no Brasil, uma novidade. As pequenas tiragens com as indicações "desta obra foram tirados 25 exemplares em papel especial para bibliófilos, marcados com as letras de A a Z", só há muito pouco tempo estão sendo feitas com certa regularidade pelas nossas casas editoras. Compreende-se o fato. É que antes da guerra não havia mercado para tal empresa. [...] As edições de luxo que começam a aparecer com frequência indicam desde já que o negócio não é dos piores. Pelo menos, há quem compre livros de duzentos, quinhentos e mil cruzeiros. Um jovem livreiro paulista percebeu logo no início de sua atividade de editor, o clima psicológico do mercado, com o lançamento dos primeiros volumes da excelente Biblioteca Histórica Brasileira. Era um golpe de audácia. Até então, as edições de luxo só entravam nas cogitações de um ou outro intelectual requintado: um Aluísio de Castro, um Ronald de Carvalho, um Guilherme de Almeida, um Gilberto Freyre. O livreiro paulista soube aproveitar inteligentemente a experiência particular, num momento em que não sofreria a concorrência do livro estrangeiro. Não há dúvida de que José de Barros Martins abriu caminho para o surto das edições de luxo, em base comercial. (Barbosa, 1944, p.315 apud Sorá, 2010, p. 372).

Interessante notar que nesse mesmo ano de 1943, Castro Maya lançou o primeiro título da Sociedade dos Cem Bibliófilos do Brasil, edições que segundo Chico Homem de Melo, representa "a maior iniciativa já feita no Brasil no campo dos livros de luxo". ${ }^{9}$ Há similaridades nas coleções de Maya e Martins. Tanto as edições dos Cem Bibliófilos do Brasil quanto a coleção BLB contaram com ilustradores como Di Cavalcanti, Tomás Santa Rosa e Aldemir Martins; também em ambas foram publicadas obras de autores consagrados, como por exemplo, Machado e Assis e Castro Alves. É notável que na coleção de Maya a variedade de projeto gráfico, diversidade de papel, acabamento e impressão dos livros, teve maior experimentação e investimento. Todavia, enquanto a tiragem da coleção de Maya era destinada exclusivamente a um grupo seleto de bibliófilos - os sócios que financiavam a produção dos livros -, a coleção BLB estendia o alcance de edição especial para um público mais amplo, ou como nas palavras acima de Barbosa, "edições de luxo em base comercial". Essa iniciativa da BLB foi talvez a maior diferença entre as duas coleções e, possivelmente, a de maior importância cultural da Martins: a de ter subsidiado com recursos da própria editora e comercializado a preços acessíveis edições especiais aos leitores em geral.

Segundo Sorá, as grandes editoras do período, como a Companhia Editora Nacional e a José Olympio imitaram, anos mais tarde, o filão de luxo da brasiliana aberto por Martins. Os editores constataram a perda progressiva de prestígio dos formatos convencionais em que foram lançados e a baixa rentabilidade econômica dos mesmos. No decorrer de 1940-1950, começaram a dar mais espaço a edições ricamente ilustradas, com papéis de melhor qualidade e em séries paralelas de grande formato. (SORÁ, 2010, p. 375)

\section{As edições especiais}

A seguir iremos identificar os elementos gráficos que distinguem as edições especiais das edições comuns da BLB, publicadas na década de 1940. Para tanto, será

\footnotetext{
${ }^{9}$ MELO, RAMOS, 2011, p.206.
}

$13^{\circ}$ Congresso Brasileiro de Pesquisa e Desenvolvimento em Design, Univille, Joinville (SC) 
feita uma análise gráfica aplicando o método de Twyman (1979), em que serão observados na composição dos livros os três grupos de elementos da linguagem gráfica: verbais, pictóricos e esquemáticos. O autor sugere que a linguagem - entendida pelos linguistas como "falada e escrita" -, seja interpretada no âmbito do Design Gráfico como verbal e pictórica e propõem um método de análise do objeto gráfico a partir de situações mais comuns de comunicação, como a audição ou a visão. Neste sentido, a linguagem visual é a representação gráfica da linguagem falada (auditiva) que pode ser gráfica e não-gráfica. Aqui nos interessa o sentido atribuído por Twyman à linguagem gráfica. Ao ser caracterizada por verbal se entende que é a representação gráfica da fala que pode ser tipográfica ou escrita à mão; por pictórica se entende que é a produção de imagens feitas artificialmente e que remetem à aparência ou estrutura de algo real ou imaginado; por esquemática se entende que é a representação de formas gráficas que não incluem palavras, números ou imagens pictóricas. (MARTINS, LIMA, LIMA, 2015, p.942-943).

\subsection{Capa}

O design da capa dos livros da BLB padroniza as edições e reafirma visualmente o caráter de coleção. Com o objetivo de fazer uma análise da linguagem gráfica das capas, veremos a seguir como se comportam na diagramação os elementos verbais, pictóricos e esquemáticos. A estética da capa da coleção assemelha-se a uma folha de rosto, em que os elementos verbais (nome da coleção, número do volume, nome do autor, título da obra, nome da editora e local) estão centralizados na página e dispostos numa sequência de leitura (de cima para baixo, da esquerda para direita) e diferenciados hierarquicamente em função do peso e tamanho do corpo das letras. Porém, o destaque vai para o título, elemento verbal de maior peso, cujas iniciais na cor vermelha se torna um elemento cromático diferenciador. (Figura 2).

Figura 2 - Capas dos livros da BLB publicadas em 1940
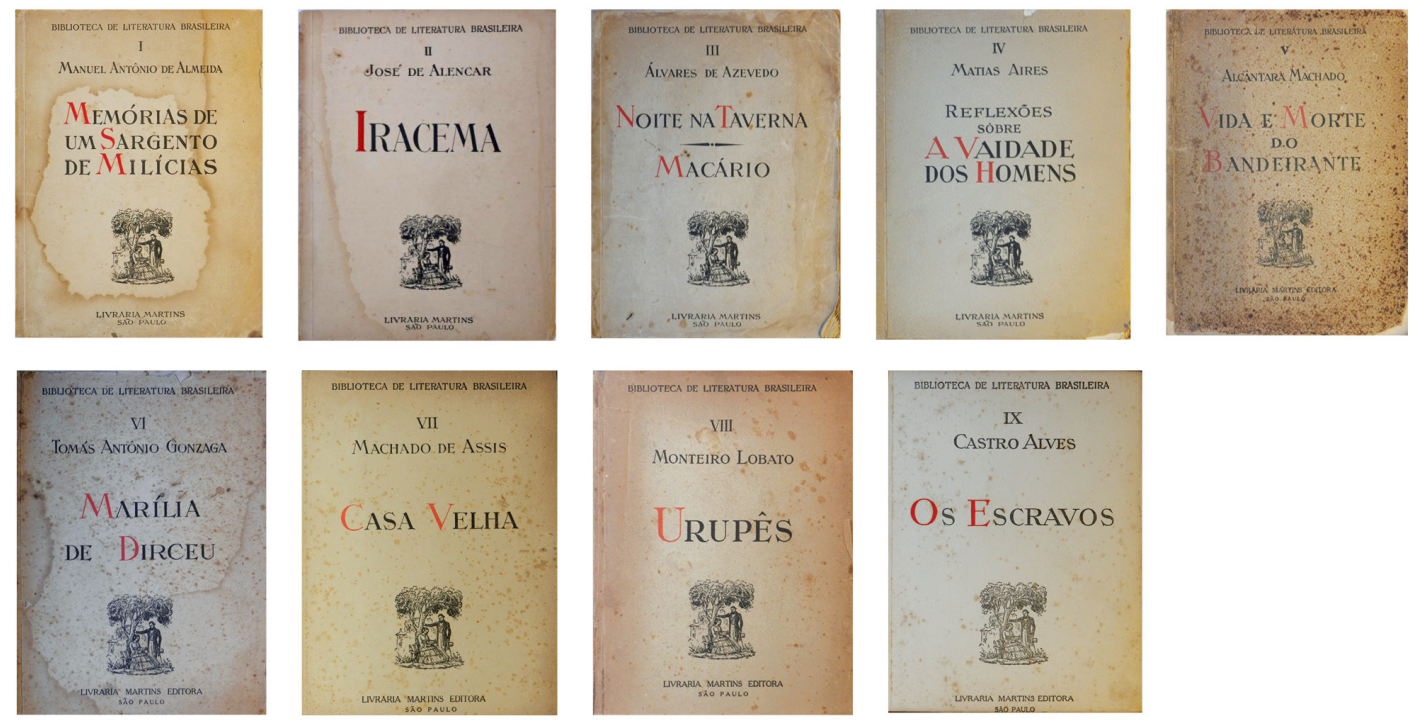

Fonte: Acervo pessoal

O elemento pictórico presente nas capas é sempre o mesmo, a identidade (símbolo) da coleção BLB. A imagem mostra um casal recostado numa árvore frondosa, com um casario ao fundo. A moça que lê está sentada e ao seu lado um rapaz em pé acompanha a leitura. A ilustração foi feita por José Wasth Rodrigues, como se vê no 
elemento verbal que consta do detalhe da imagem no canto inferior direito - a assinatura "w." do artista. (Figura 3).

Figura 3 - Símbolo da coleção e assinatura de J. Wasth Rodrigues
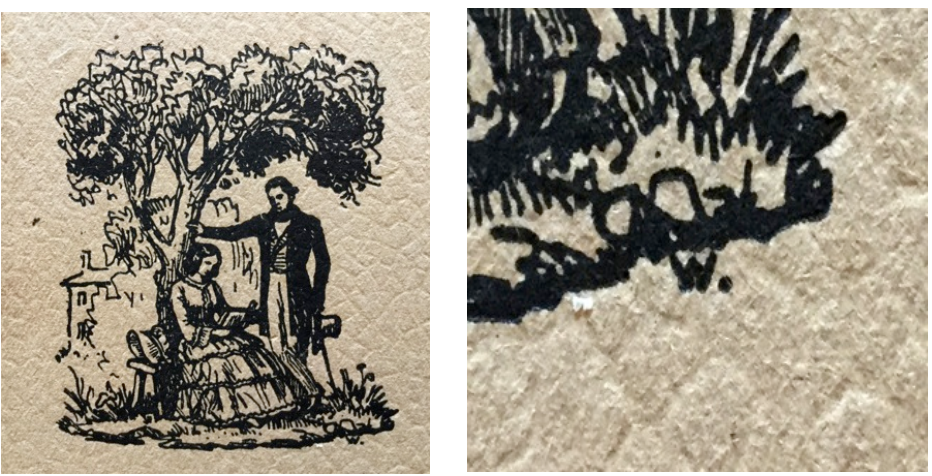

Fonte: Acervo pessoal

A assinatura de J. Wasth Rodrigues é o registro de autoria do artista, mas para além disso, este elemento verbal transfere à ilustração o prestígio de obras de arte assinadas (como por exemplo se faz nas gravuras) e embute na imagem uma condição mais singular. A quarta-capa, em sua maioria, é composta por elementos verbais e pictóricos. A identidade (símbolo) da Livraria Editora Martins, é um elemento pictórico que foi redesenhado por J. Wasth Rodrigues para a coleção, no qual também consta o elemento verbal "w". A comparação entre as ilustrações do símbolo da editora impressa na papelaria da Martins (cartões e press-release) que datam do mesmo período, como também, no ex-libris do editor, encontrado em um de seus livros que hoje estão aos cuidados de José Fernando de Barros Martins, herdeiro da editora. Nas reproduções abaixo, são nítidas as diferenças de traço das ilustrações e das diversas versões que o elemento pictórico teve. (Figura 4).

Figura 4 - As diversas versões da identidade (símbolo) da editora, com destaque (circulado em vermelho, acima) da assinatura de J. Wasth Rodrigues, novamente marca o elemento verbal na imagem
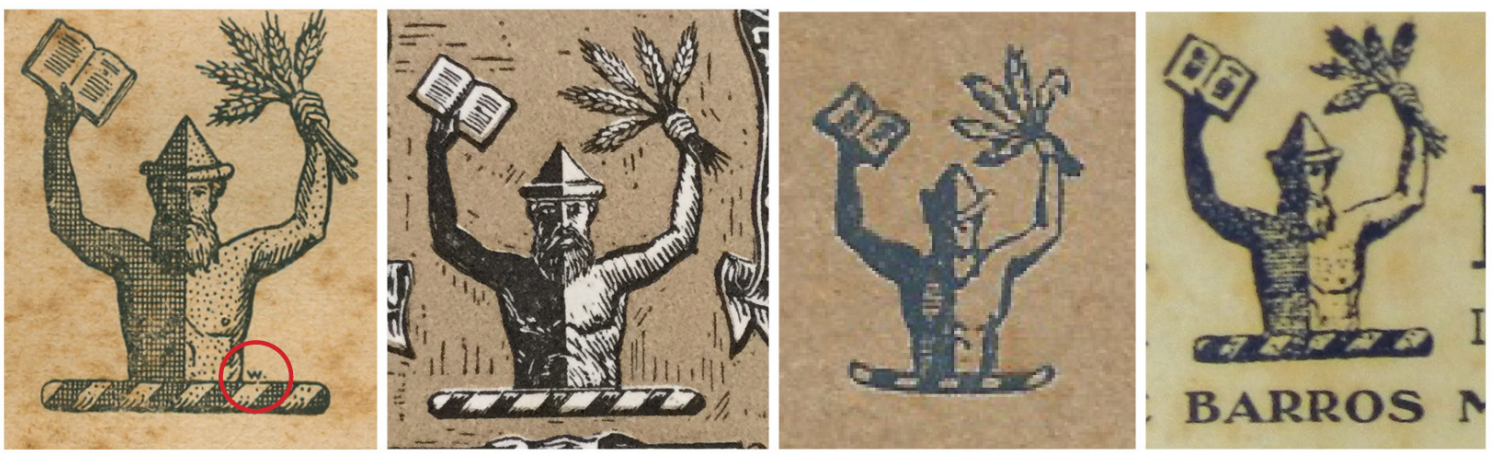

Fonte: Acervo pessoal

Interessante notar que desde as publicações de livros de literatura, produzidos no Brasil na década de 1920, este recurso de imprimir uma pequena ilustração (centralizada na folha), como se fosse uma vinheta encerrando a publicação, é usado também para reforçar a marca da editora. Por fim, o elemento verbal que consta na quarta-capa é a informação a respeito da gráfica responsável pela impressão do livro, no caso, a Empresa Gráfica da Revista dos Tribunais Ltda., em São Paulo (Figura 5). 
Figura 5 - Quarta-capa dos livros da BLB publicados em 1940. No centro da página está localizado o símbolo da editora, elemento pictórico, e abaixo, à esquerda, o elemento verbal (no destaque), com os dados da gráfica que imprimiu o livro

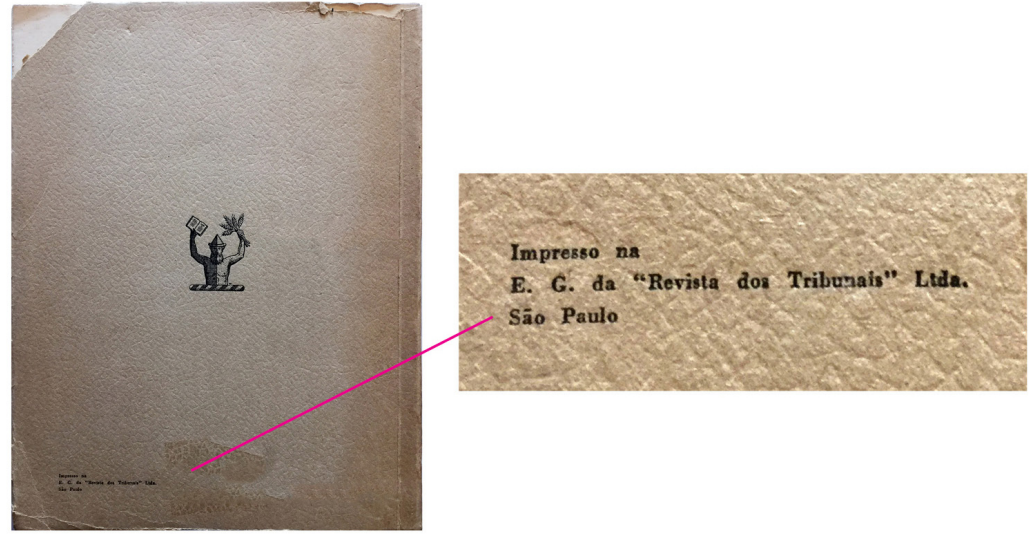

Fonte: Acervo pessoal

$\mathrm{Na}$ capa, vemos que o aspecto gráfico que difere as "edições especiais" das "edições comuns" é de ordem material, ou seja, a qualidade do papel. Como exemplo desta variação, analisamos um exemplar para cada tipo de edição de Urupês, o oitavo volume da coleção BLB, impresso em setembro de 1944. (Figura 6). Da tiragem de 2.120 exemplares, 120 exemplares foram impressos em papel Westerledger e os 2.000 exemplares restantes foram impressos em papel bouffant de $1^{\text {a }}{ }^{10}$

Figura 6 - Capas de Urupês: edição especial (à esquerda), $n^{0} 31$; edição comum (à direita), $n^{0} 1832$ ambas da mesma tiragem produzida em 1944
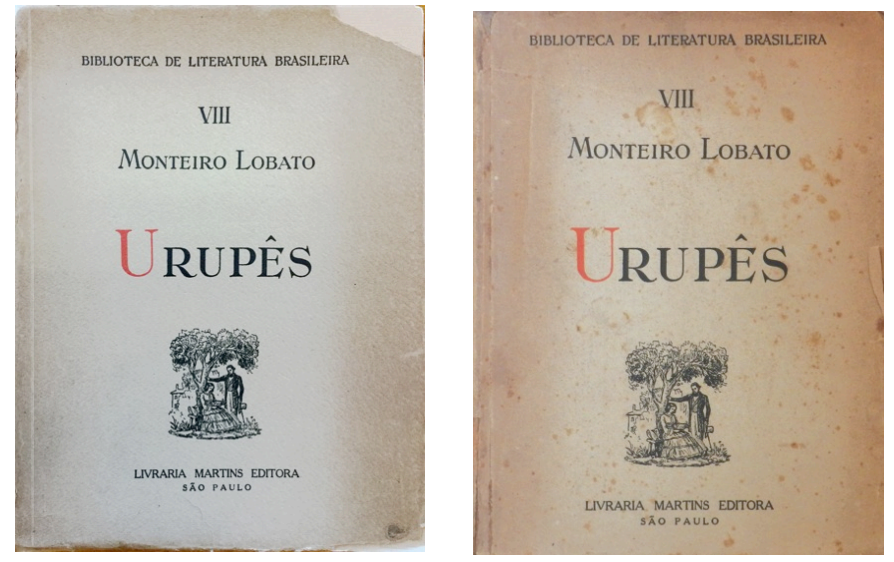

Fonte: Biblioteca Brasiliana Guita e José Mindlin/USP (edição especial) e Acervo pessoal (edição comum)

\footnotetext{
${ }^{10}$ De acordo com as definições de Lorenzo Baer a respeito das qualidades dos papéis para impressão, "o papel bouffant ou bufon, do francês bouffant, particípio presente de bouffer (tornar-se cheio), também conhecido como featherweight paper (papel peso-pluma) e bulk paper (papel volumoso), o papel bouffant é leve, encorpado e fofo. Não-acetinado, quase sem calandragem, possui um acabamento áspero. Vendido nos formatos $66 \times 96 \mathrm{~cm}, 76 \times 112 \mathrm{~cm}$ e $87 \times 114 \mathrm{~cm}$, nas gramaturas de 63 a 110 $\mathrm{g} / \mathrm{m}^{2}$, é utilizado em vasta escala na impressão de livros". (BAER, 1995, p.173). A qualidade "de primeira", não é atribuída pela editora, mas sim, o nome dado ao papel buffant de $1^{a}$, no qual não há a inclusão de pasta mecânica na sua fórmula. Quando este insumo passa a fazer parte da composição do papel, o bouffant é qualificado como papel bouffant de $2^{a}$. Fonte" https://pt.slideshare.net/Filllipe/tiposde-papel-32079245.
} 
Fica evidente, comparando as duas capas acima, da mesma tiragem, o desgaste sofrido pelo papel de qualidade inferior - o bouffant, usado na edição comum (à direita). Também, são significativas a coloração mais amarelada desse papel e a fragilidade de estrutura da fibra, que o deixa mais quebradiço e sujeito a danos em função do tempo.

\subsection{Miolo}

Um dos elementos que constituem peritexto editorial ${ }^{11}$ de uma obra é a "justificação de tiragem", ou seja, é o aviso do editor sobre a composição material da obra (escolha do papel e composição tipográfica), além de informações específicas sobre a tiragem e o que mais for necessário ao avisar o leitor de quais parâmetros editoriais e gráficos deram forma de livro a um texto. (GENETTE, 2009, p.35). O aviso ou justificação se localiza nas páginas iniciais do livro ou no colofão, uma das últimas páginas. No caso das edições da coleção BLB, a justificação de tiragem aparece geralmente na segunda página. As edições francesas - importadas na época da Livraria Martins - trazia esta informação no início da obra. (Figura 7).

Figura 7 - Justificação de tiragem de exemplares franceses das décadas de 1920-1930, publicados pelas editoras Librairie de France e Éditions du Trianon, nos quais se pode obter informações a respeito das diferenciações entre a tiragem especial e a comum
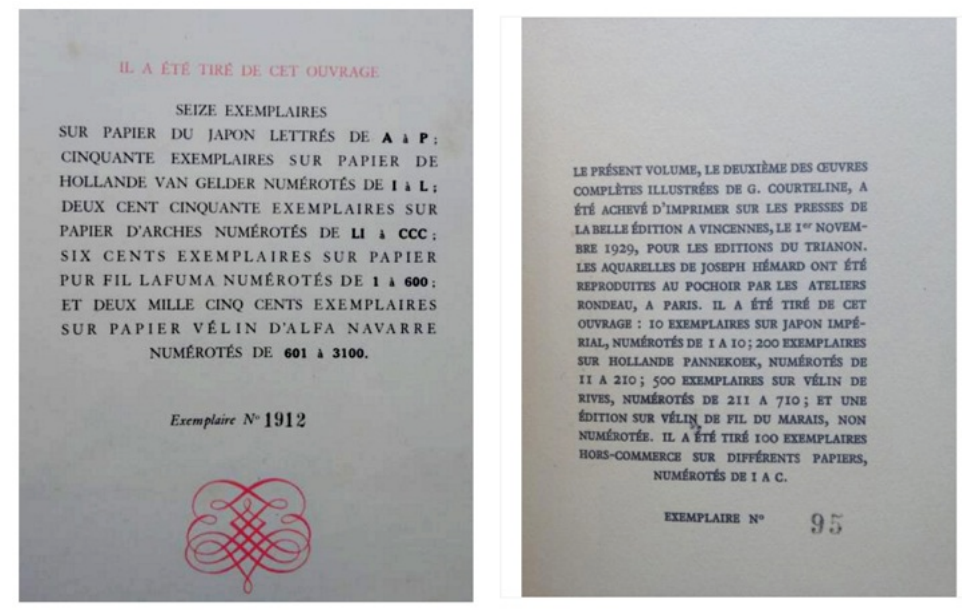

Fonte: Biblioteca Brasiliana Guita e José Mindlin / USP (edição especial) e Acervo pessoal (edição comum).

A imagem reproduzida à esquerda se trata do exemplar de $n^{\circ} 1912$ da obra Florilège des Conteurs Galants du XVIII Siècle, ilustrada por Adrien Bagarry, em 1932, publicada pela Librairie de France; ao lado, à direita, o aviso de tiragem se trata do exemplar n 95 da obra Boubouroche, de Georges Courteline, ilustrada por Joseph Hémard, em 1929, publicada pela Éditions du Trianon. As informações contidas nas duas imagens evidenciam a importância da qualidade do papel, elemento de diferenciação dos exemplares, atribuindo-lhes maior ou menor valor. O melhor papel é usado na impressão dos primeiros exemplares da tiragem. Estas variações e especificações das edições contidas na justificação de tiragem das edições francesas podem ter influenciado Martins ao adotar padrão semelhante na BLB.

11 Genette denomina peritexto editorial como sendo toda a zona do peritexto que se encontra sob responsabilidade direta e principal (mas não exclusiva) do editor, ou talvez, de maneira mais abstrata porém com maior exatidão, da edição, isto é, do fato de um livro ser editado, e eventualmente reeditado, e proposto ao público sob uma ou várias apresentações mais ou menos diferentes. (GENETTE, 2009, p.21) 
No caso da coleção da Martins, o papel de qualidade no miolo das edições é um elemento de diferenciação, e quanto melhor a qualidade - como a do papel Westerledger - mais limitados eram os exemplares. No exemplo que temos deste papel utilizado em Urupês, de 1944, conseguimos notar que até a marca d'água ou marca a seco do papel, gravada a pressão depois dele ter sido fabricado e que, como a filigrana, se vê por transparência $^{12}$, é indício de requinte e distinção (Figura 8).

Figura 8 - Marca a seco do papel da obra Urupês, de 1944

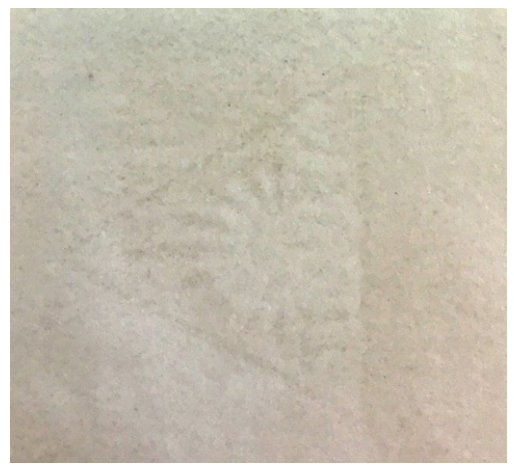

Fonte: Acervo pessoal

Outra referência importante que se encontrou no decorrer desta pesquisa, foi a obra Lírica de Camões, de José Maria Rodrigues e Afonso Lopes Vieira, de 1932, publicada pela Imprensa da Universidade de Coimbra. No livro, que hoje pertence ao herdeiro da editora, mas fazia parte da biblioteca do editor José de Barros Martins, vê-se na justificativa de tiragem outros elementos verbais, os quais iremos identificar nas justificativas de tiragem da coleção BLB, tais como: a numeração escrita à mão e a assinatura do autor ou editor obra. (Figura 9).

Figura 9 - Justificação de tiragem de exemplar português da décadas de 1930, com numeração anotada à mão e assinada

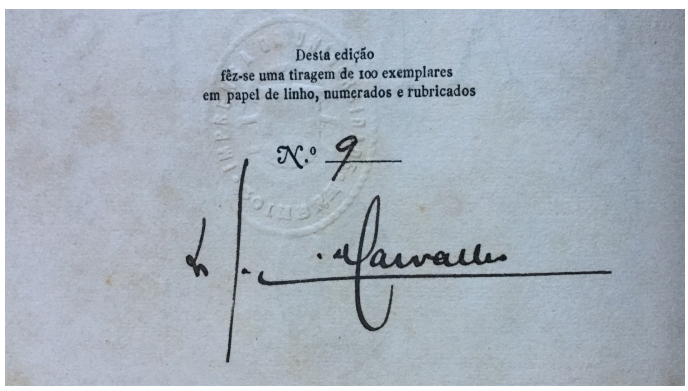

Fonte: Acervo de José Fernando de Barros Martins

As variações das edições especiais da BLB vão além do tipo de papel. A exemplo da edição portuguesa, em que a numeração é anotada à mão, no exemplar de $n^{0} \mathrm{~V}$ da edição especial de Reflexões da Vaidade dos Homens, quarto volume da coleção BLB, ilustrado por Tomás Santa Rosa, impresso em maio de 1942, o mesmo recurso de distinção é adotado. No exemplar da edição comum, exemplar $n^{0} 623$, desta mesma tiragem, a numeração foi impressa em tipografia (Figura 10).

${ }^{12}$ FARIA, PERIÇÃO, 2008, p.482.

$13^{\circ}$ Congresso Brasileiro de Pesquisa e Desenvolvimento em Design, Univille, Joinville (SC) 
Figura 10 - Justificação de tiragem dos exemplares de Reflexões sobre a Vaidade dos Homens: edição especial (à esquerda), com elemento verbal escrito à mão e o da edição comum (à direita), com elemento verbal impresso em tipografia.

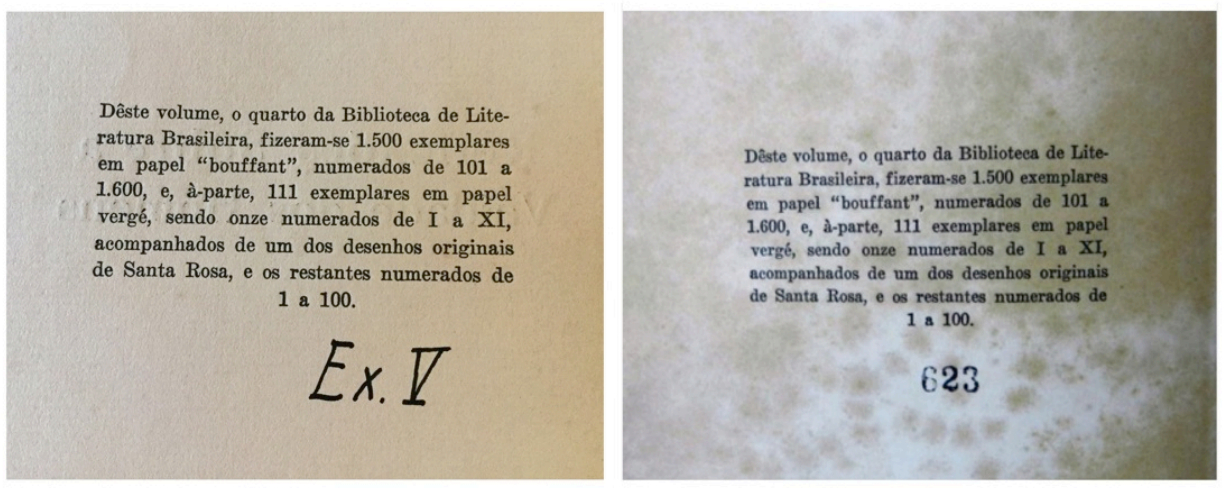

Fonte: Acervo pessoal

Ainda com relação à grafia manuscrita, que configurava às edições especiais um elemento verbal de diferenciação e, por conseguinte, atribuía valor ao exemplar, temos outros dois exemplos da coleção BLB: a assinatura do editor e a assinatura do autor. Esses exemplares eram restritos à numeração limitada, tal como vemos na justificativa de tiragem das obras: Urupês, de Monteiro Lobato, exemplar $n^{0} 31$, ilustrado por Paim, impresso em 1944; Vida e morte do Bandeirante, de Alcântara Machado, exemplar $n^{0}$ 60, ilustrado por J. Wasth Rodrigues, em 1943; e, em Os escravos, de Castro Alves, exemplar $n^{0} 08$, ilustrado por Di Cavalcanti, impresso em 1947. (Figura 11).

Figura 11 - Amostras das assinaturas, da esquerda para direita: de Monteiro Lobato e as demais do editor José de Barros Martins
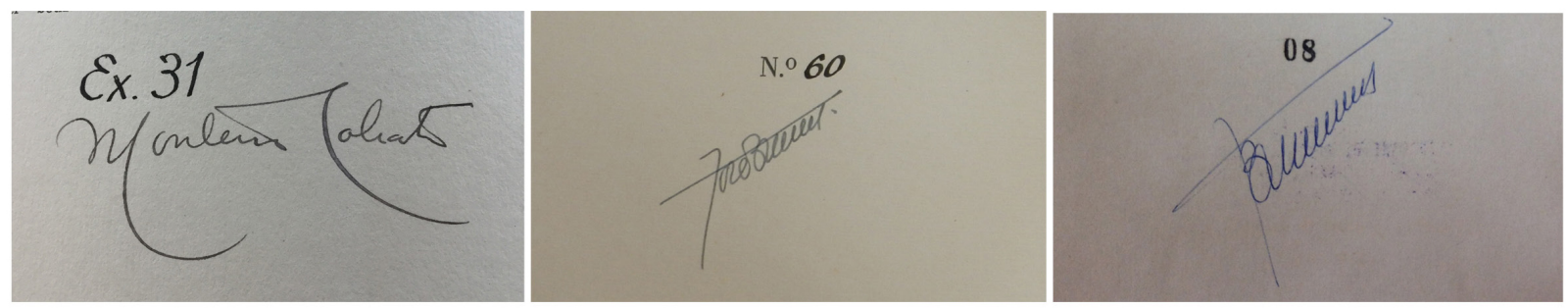

Fonte: Biblioteca Brasiliana Guita e José Mindlin/ USP, Acervo pessoal e Biblioteca da FFLCH/USP

Uma particularidade do conjunto acima é o exemplar $n^{0} 8$ de Os escravos (última imagem). Nela, vemos a numeração impressa em tipografia e apenas a assinatura do editor à mão. Do conjunto das edições especiais analisadas até agora, esta é a única ocorrência de numeração limitada em que o número do exemplar é impresso em tipografia e não manuscrito.

Os elementos pictóricos que se destacam nos exemplares especiais, os quais não constam das edições comuns, foram identificados em duas justificativas de tiragem: a primeira, no exemplar de $n^{0} 5$ da obra Reflexões da Vaidade dos Homens, de Matias Aires, ilustrada por Santa Rosa (Figura 12) e a segunda, em Vida e morte do Bandeirante, exemplar $n^{0} 60$, ilustrado por J. Wasth Rodrigues. 
Figura 12 - Justificativa de tiragem do exemplar de $n^{0} 5$ da obra Reflexões da Vaidade dos Homens, ilustrada por Santa Rosa.

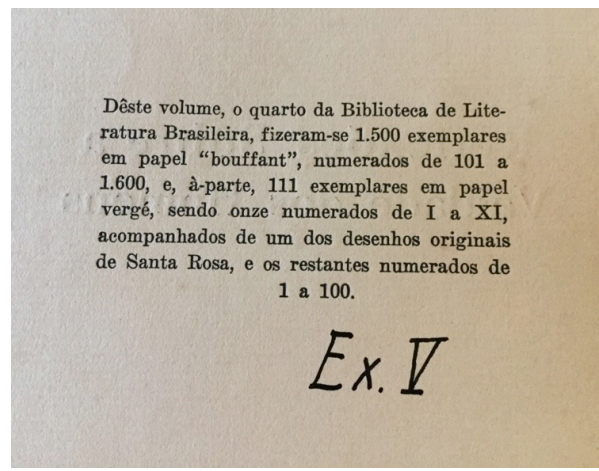

Fonte: Acervo pessoal

Em Reflexões da Vaidade dos Homens a edição especial, de um total de 101 exemplares, os números 1 a 11 são acompanhados por desenhos originais do artista Tomás Santa Rosa. O desenho a nanquim é protegido por um papel mais fino, semelhante ao de seda, encartado ao final do livro. (Figura 13). No total foram feitas 11 ilustrações e por esta razão a tiragem limitadíssima de 11 exemplares se justifica pela quantidade dos desenhos originais.

Figura 13 - Amostras das últimas páginas do livro com o desenho original de Tomás Santa Rosa, encartado no exemplar número $\mathrm{V}$, da obra Reflexões da Vaidade dos Homens
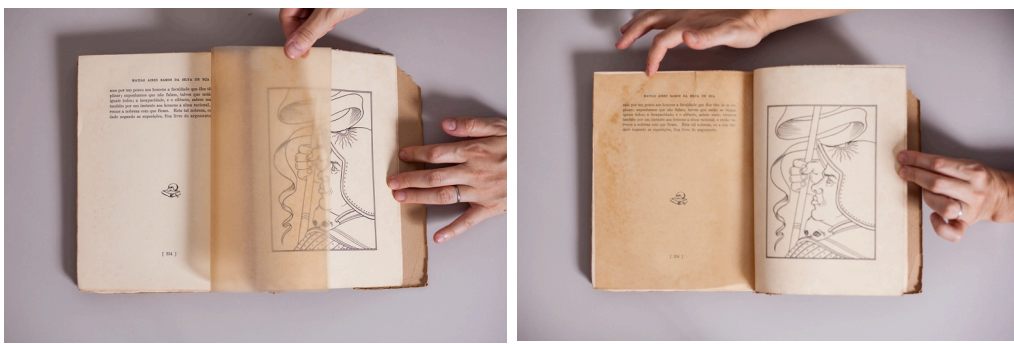

Fonte: Acervo pessoal

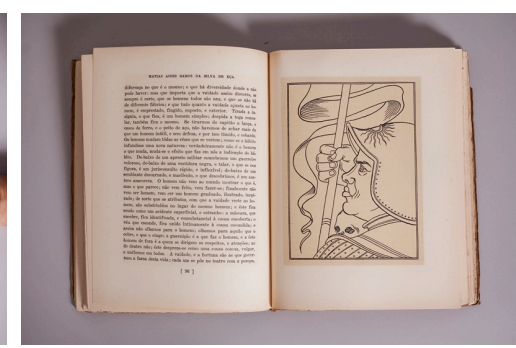

$\mathrm{Na}$ imagem seguinte (no centro), podemos ver a impressão do desenho original, transferido para uma matriz (um clichê) e impresso em tipografia. Na última imagem, vemos a ilustração gravada ao lado bloco de texto e enquadrada numa segunda cor, um amarelo claro.

Na edição de Vida e morte do Bandeirante, ilustrado por J. Wasth Rodrigues, além dos desenhos originais que formam o conjunto dos 25 primeiros números da edição, há também uma diferenciação dos exemplares de número 26 a 75, os quais são acompanhados por uma "suíte das ilustrações em sépia". Na justificativa de tiragem do exemplar de número 60 há a descrição das variantes que caracterizam os exemplares denominados "de luxo" pela editora (os mesmos denominados "especiais", em outros títulos da coleção) e os comuns. O interessante, como veremos adiante, é que no exemplar analisado para este estudo a categoria que ele se encaixa é a de luxo "secundária", ou seja, a segunda de maior prestígio. Além dos elementos verbais, como a assinatura do editor e a numeração à mão, o elemento pictórico que valoriza a edição é o encarte, nas últimas páginas, da suíte em sépia com a reproduções de todas as ilustrações do livro. (Figura 14). 
Figura 14 - Justificativa de tiragem da obra Vida e morte do Bandeirante e, ao lado, acima está reproduzida a página dupla impressa com os elementos verbais e pictóricos que a constitui e, abaixo, a mesma dupla, integra o conjunto "especial" da suíte em sépia, na qual são impressos somente os elementos pictóricos

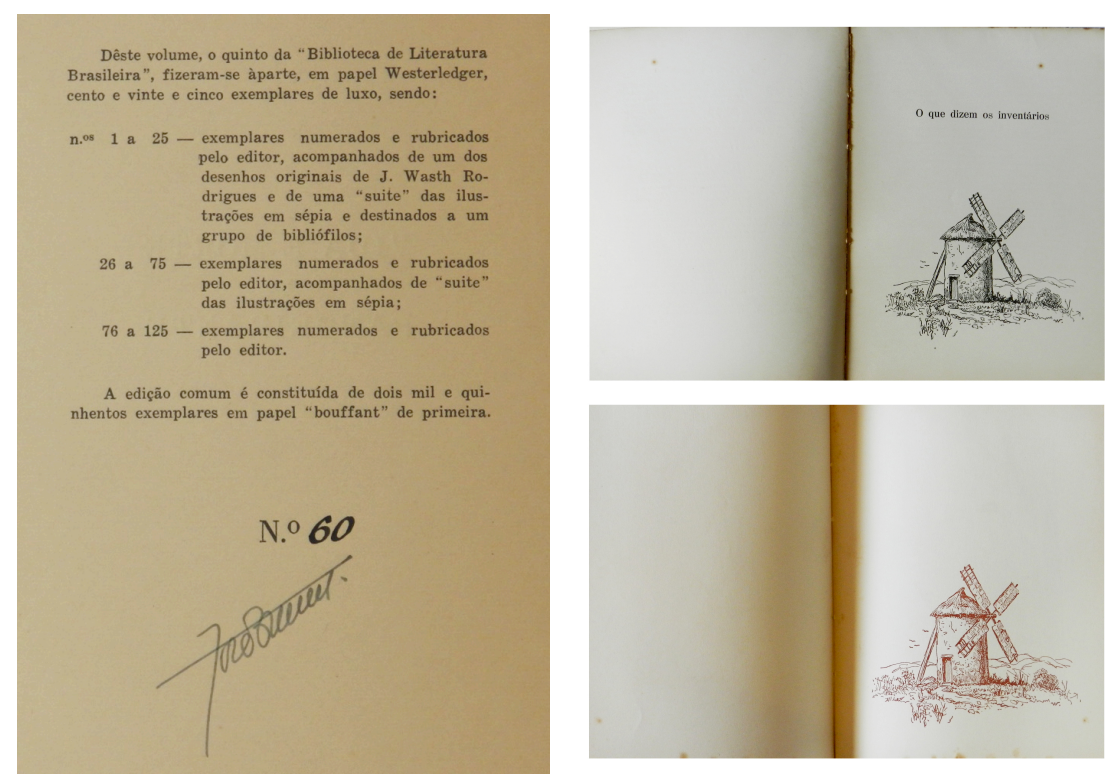

Fonte: Acervo pessoal

Por último, vale notar que a justificação de tiragem aparece impressa em todas as edições - especiais e comuns. O que para a edição comum (como se vê nas imagens anteriores) não seria necessário, visto que apenas nas edições limitadas precisaria ser indicado os critérios de distinção das edições. Genette comenta que este fato não quer dizer, porém, que a indicação não interesse aos leitores (das edições comuns), que encontram na justificação de tiragem uma informação bibliográfica como qualquer outra e, talvez, a ocasião de um desgosto, cuja ideia só pode aumentar o prazer dos privilegiados. "Isso porque não basta ser feliz, é preciso também ser invejado". (GENETTE, 2009 p. 37).

\section{Considerações finais}

O objetivo deste trabalho foi identificar os elementos gráficos que caracterizam as edições especiais da BLB, publicadas pela Livraria Martins Editora na década de 1940. Por meio da observação dos elementos verbais, pictóricos e esquemáticos - modelo de análise proposto por Twyman (1979) -, pode-se verificar de que maneira os elementos gráficos e editoriais se manifestam e se articulam em função da justificativa de tiragem das edições. No entanto, para compreender as motivações do editor e da editora em publicar as edições especiais, foi preciso fazer um estudo mais apurado a respeito das origens da editora, antes livraria e importadora. Também, com intuito de reconhecer quais parâmetros de edições especiais, principalmente no que se refere às edições estrangeiras influenciaram José de Barros Martins, foi preciso entender o momento histórico-social do período da produção dos livros da coleção BLB, como também, da mudança de livraria para editora. Neste contexto, notamos que havia um público, com interesse e capital, que justificou a produção de livros de luxo e o projeto editorial da Martins. O livro passou a ser um objeto de distinção social, com valor de mercado que variava conforme as características físicas do projeto e, principalmente, a mudança do papel da impressão, que embute na sua a marca d'água a ideia de qualidade da produção gráfica. O singular das edições especais se deve ao fato de identificarmos que as distinções entre edições 
comuns e especiais, inicialmente concentradas nos elementos pictóricos e verbais, ajuda a estabelecer duas dimensões de valor: uma artística das artes visuais como as gravuras e outra verbal, as assinaturas, cujo valor está na relação direta com autores e editores. Ambos são 'originais', aspectos simbolicamente valorizados pelos colecionadores. Vale ressaltar, que não foi encontrado, por meio da análise, registro de elementos esquemáticos que marcassem algum tipo de distinção nos exemplares das edições especiais.

É notável que José de Barros Martins, diferente do que se constatou a respeito das características de edição de luxo nas editoras estrangeiras e, mesmo, nas contemporâneas nacionais do período, como a José Olympio, conseguiu articular e comercializar em maior escala um modelo de publicação de luxo, na década de 1940, até então (pelo que se lê na fortuna crítica do período) inédito no mercado editorial brasileiro.

\section{Referências}

BAER, Lorenzo. Produção gráfica. 4a edição. São Paulo: Editora SENAC São Paulo, 2002.

BRITO, Mario da Silva. Breve história de uma editora. São Paulo: Livraria Martins Editora, 1967.

FARIA, Maria Isabel Ribeiro de; PERICÃO, Maria da Graça. Dicionário do Livro: da escrita ao livro eletrônico. São Paulo: Edusp, 2008.

GENETTE, Gérard. Paratextos Editoriais. São Paulo: Ateliê Editorial, 2009

HALLEWELL, Laurence. O livro no Brasil: sua história. Trad. Maria da Penha Villa lobos e Lólio Lourenço de Oliveira. São Paulo: T.A. Queiroz; São Paulo: Edusp, 2005.

LIMA, Yone Soares de. A ilustração na produção literária. São Paulo - década de vinte. São Paulo: IEB/USP, 1985.

MARTINS, Fernanda O.; LIMA, Edna Cunha; LIMA, Guilherme Cunha. Análise de duas propostas metodológicas para a pesquisa em História do Design Gráfico. $7^{0}$ Congresso Internacional de Design da Informação, CIDI 2015.

MARTINS FILHO, Plínio. Manual de editoração e estilo. Campinas: Editora da Unicamp; São Paulo: EDUSP; Belo Horizonte: Editora UFMG, 2016.

MELO, Chico Homem de; RAMOS, Elaine (Orgs.). Linha do tempo do design gráfico no Brasil. São Paulo: Cosac Naify, 2011.

PAIXÃO, Fernando. Momentos do livro no Brasil. São Paulo: Editora Ática, 1997.

Revista da Biblioteca Mário de Andrade $n^{0}$ 67, 2012.

SORÁ, Gustavo. Brasilianas: José Olympio e a gênese do mercado editorial brasileiro. São Paulo: Edusp, 2010.

TWYMAN, Michael. A schema for the study of graphic language. In: KOLERS, $P$. A.; WROLSTAD, M. E.; BOUMA, H. (orgs.). Processing of visible language. New York: Plenum, p. 17-50, 1979.

Entrevista com José Fernando de Barros Martins em 16/10/2013 e 18/10/2017 